medRxiv preprint doi: https://doi.org/10.1101/2021.07.15.21260570; this version posted July 19, 2021. The copyright holder for this preprint (which was not certified by peer review) is the author/funder, who has granted medRxiv a license to display the preprint in perpetuity. It is made available under a CC-BY-NC-ND 4.0 International license.

\title{
Glycophorin C in atherosclerotic plaque is associated with major adverse cardiovascular events after carotid endarterectomy.
}

Joost M. Mekke ${ }^{1}$, Tim R. Sakkers ${ }^{6}$, Maarten C. Verwer ${ }^{1}$, Noortje A.M. van den Dungen², Y. Song ${ }^{5}$, C. Miller ${ }^{3,4,5}$, Gerard Pasterkamp ${ }^{2}$, Michal Mokry ${ }^{2,7}$, Hester M. den Ruijter ${ }^{6}$, Dominique P. V. de Kleijn ${ }^{1.8}$, Gert J. de Borst ${ }^{1}$, Saskia Haitjema ${ }^{2 *}$, Sander W. van der Laan ${ }^{2 *}$

\section{Affiliations.}

${ }^{1}$ Department of Vascular Surgery, Division of Surgical Specialties, University Medical Center Utrecht, Utrecht University, Utrecht, the Netherlands.

${ }^{2}$ Central Diagnostic Laboratory, Division Laboratories and Pharmacy, University Medical Center Utrecht, Utrecht University, Utrecht, the Netherlands.

${ }^{3}$ Center for Public Health Genomics, University of Virginia, Charlottesville, VA 22908, USA

${ }^{4}$ Department of Biochemistry and Molecular Genetics, University of Virginia, Charlottesville, VA 22908, USA

${ }^{5}$ Department of Public Health Sciences, University of Virginia, Charlottesville, VA 22908, USA

${ }^{6}$ Laboratory of Experimental Cardiology, Department of Cardiology, Division Heart and Lungs, University Medical Center Utrecht, University Utrecht, Heidelberglaan 100, 3508 GA, Utrecht, The Netherlands 7 Department of Cardiology, Division Heart and Lungs, University Medical Center Utrecht, University Utrecht, Heidelberglaan 100, 3508 GA, Utrecht, The Netherlands

8 Netherlands Heart Institute, Moreelsepark 1, 3511 EP, Utrecht, The Netherlands

*Shared last authorship

\section{Abstract. \\ Introduction}

Histological assessment studies have identified the presence of intraplaque hemorrhage (IPH) as an indicator of plaque instability and resulting ischemic cerebral sequelae. Although the presence of IPH has been studied extensively in relation to neurological symptoms preceding carotid endarterectomy (CEA) or as a predictor for postoperative risk of major adverse cardiovascular events (MACE), the degree of IPH has not been studied before. Glycophorin, an erythrocyte-specific protein, has been suggested as a marker for the degree of previous hemorrhages in atherosclerotic plaque since erythrocytes are prominently present in IPH. We hypothesized that quantified plaque glycophorin $\mathrm{C}$, as a proxy for the degree of IPH, is associated with destabilizing plaque characteristics, preprocedural symptoms, and increased postoperative risk for MACE.

\section{Methods}

We quantified glycophorin $\mathrm{C}$ and six other plaque characteristics with the slideToolkit method. We used human atherosclerotic plaque samples from 1971 consecutive asymptomatic and symptomatic (carotid endarterectomy) patients in the Athero-Express Biobank.

\section{Results}

The total area of glycophorin C in plaque was larger in individuals with a plaque with IPH compared to individuals with plaque without IPH $(\mathrm{p}<0.001)$. Quantified glycophorin $\mathrm{C}$ was significantly associated with ipsilateral pre-procedural neurological symptoms (OR:1.27, 95\% $\mathrm{Cl}: 1.06-1.41, \mathrm{p}=0.005)$. In addition, quantified glycophorin C was independently associated with an increased postoperative risk for MACE (HR:1.31, $95 \% \mathrm{Cl}: 1.01-1.68, \mathrm{p}=0.04)$. Stratified by sex, quantified glycophorin $\mathrm{C}$ was associated with an increased postoperative risk for MACE in male patients (HR:1.50,95\% $\mathrm{Cl}: 1.13-1.97, \mathrm{p}=0.004)$, but not in female patients (HR:0.70, 95\% Cl:0.39-1.27, $\mathrm{p}=0.23$ ).

\section{Conclusion}

Quantified glycophorin $\mathrm{C}$, as a proxy for the degree of IPH, was independently associated with the presence of $\mathrm{IPH}$, symptomatic preprocedural symptoms, and with an increased three-year postoperative risk of MACE. These findings indicate that quantified plaque glycophorin $\mathrm{C}$ can be considered as a marker for identifying male patients with a high residual risk for secondary MACE after CEA.

\section{Keywords}

Atherosclerosis, Carotid endarterectomy, Glycophorin, Intraplaque hemorrhage, Major adverse cardiovascular ENefts: This preprint reports new research that has not been certified by peer review and should not be used to guide clinical practice. 
medRxiv preprint doi: https://doi.org/10.1101/2021.07.15.21260570; this version posted July 19, 2021. The copyright holder for this preprint

(which was not certified by peer review) is the author/funder, who has granted medRxiv a license to display the preprint in perpetuity. It is made available under a CC-BY-NC-ND 4.0 International license .

\section{Introduction.}

Carotid endarterectomy (CEA) is a proven and beneficial therapy for the treatment of moderate to severe carotid stenosis to reduce the risk of recurrent ipsilateral stroke in symptomatic patients ${ }^{1}$. Despite improved secondary prevention, consisting of risk factor management and medication use, these patients have a $25 \%$ residual risk of developing a new cardiovascular event within 3 years following carotid endarterectomy of which $13 \%$ is major adverse cardiovascular events (MACE) ${ }^{2-4}$. This residual risk is probably due to the systemic nature of atherosclerosis ${ }^{5}$. Although the carotid plaque has been removed, the progression of atherosclerotic plaques in other vascular areas continues and might result in secondary cardiovascular events after the initial CEA. The composition of the excised plaque specimen, however, can serve as a biopsy that reflects the plaque stability and progression of atherosclerosis in the other vascular territories ${ }^{4,6,7}$.

Cross-sectional pathology studies have identified atherosclerotic plaque features that might lead to cardiovascular events. These features, that contribute to plaque instability, are among others: a large lipid core, a thin fibrous cap, a large infiltrate of pro-inflammatory cells and neovascularization ${ }^{8,9}$. In addition, the presence of intraplaque hemorrhage (IPH) is recognized as one of the most important hallmarks of plaque instability ${ }^{10}$. IPH is a common phenomenon ${ }^{11}$, especially in more advanced atherosclerotic lesions and is independently associated with an increased risk of secondary cardiovascular (CV) events after carotid endarterectomy (CEA) ${ }^{4}$, in men but not in women ${ }^{12}$.

The current standard for histological examination of IPH is through the labor-intensive manual microscopic assessment of slides by a pathologist using a semi-quantitative classification method $^{13,14}$. This method scores IPH based on the presence of hemorrhagic debris consisting of a mixture of mainly intact and degenerated erythrocytes, fibrin, amorphous material and myofibroblast, which is located in the core of the plaque ${ }^{11}$. Alternatively, the presence and degree of IPH can also be visualized by immunostaining glycophorins. Glycophorins are erythrocyte specific membrane proteins that represent about $2 \%$ of the erythrocyte membrane proteins, of whom glycophorin $A$ is the most prevalent while glycophorin $C$ and $D$ are present in lower amounts ${ }^{15,16}$. Immunostaining against glycophorin identifies intact erythrocytes and membrane remnants of erythrocytes in atherosclerotic plaque and is thereby able to visualize previous hemorrhage in plaque $^{17}$.

Previous small sample size studies have used a glycophorin staining to quantify IPH through an ordinal semiquantitative scoring method of four categories ${ }^{17,18}$ or a ratio of glycophorin positive area/vessel area ${ }^{19}$. However, determining the degree of IPH by staining for glycophorin and quantifying the total area of glycophorin with a fully automated whole slide image (WSI) analysis technique, such as the SlideToolkit ${ }^{20}$, would be a less labor intensive, more accurate and reproducible method ${ }^{21}$. Although the presence of IPH in CEA specimens, scored manually by a pathologist, has been thoroughly studied in relation to neurological symptoms before CEA ${ }^{22}$ or as a predictor of CV mortality and morbidity after surgery ${ }^{4,12}$, the degree of IPH has not previously been studied.

Therefore, we aimed to quantify the degree of IPH by quantifying glycophorin $\mathrm{C}$ and explored the associations with: (i) the presence of intraplaque hemorrhage; (ii) ipsilateral pre-procedural neurological symptoms, causing an acute cerebrovascular event prior to surgery; and (iii) secondary major adverse cardiovascular events (MACE) within a 3-year period after surgery. 
medRxiv preprint doi: https://doi.org/10.1101/2021.07.15.21260570; this version posted July 19, 2021. The copyright holder for this preprint (which was not certified by peer review) is the author/funder, who has granted medRxiv a license to display the preprint in perpetuity. It is made available under a CC-BY-NC-ND 4.0 International license .

\section{Methods.}

\section{Study population}

We used the data from 1,971 patients from the Athero-Express Biobank (www.atheroexpress.nl) (Figure 1B), an ongoing prospective study of patients undergoing CEA for atherosclerotic carotid stenosis ${ }^{23}$. Indications for CEA were reviewed by a multidisciplinary vascular team according to ESVS guidelines ${ }^{1}$. Patients were recruited from the St. Antonius Hospital Nieuwegein, Nieuwegein, the Netherlands and University Medical Center Utrecht in Utrecht, the Netherlands from 2002 onwards. Individuals who agreed to participate completed standardized baseline questionnaires regarding cardiovascular risk factors, medical history and medication use prior to surgery, that were verified against medical records. Pre-operative blood samples were collected, processed and stored for future use. Plaque samples were freshly obtained during surgery and analyzed as described below. Only individuals having undergone CEA were included in the current study. The current study was conducted in accordance with the Declaration of Helsinki and was approved by the ethical boards of both hospitals. All patients provided written informed consent.

\section{Plaque processing}

Succeeding CEA, the plaque samples were immediately transferred and processed (Figure 1A). The carotid plaque was divided in parallel segments of 5-mm thickness perpendicular to the arterial axis and the segment with the greatest plaque burden, the culprit lesion, was subjected to histopathological examination, as previously described ${ }^{4,24}$. In short, the culprit lesion was fixed in $4 \%$ formaldehyde, subsequently decalcified, embedded in paraffin and cut into $5 \mu \mathrm{m}$ sections that were routinely stained for different characteristics.

\section{ExpressScan: histopathological analysis of atherosclerotic plaque characteristics}

To obtain digital whole slide images (WSIs) we set up the ExpressScan and scanned all stained sections using a Roche Ventana iScan HT slide scanner or a Hamamatsu C12000-22 Digital slide scanner and digitally stored as z-stacked TIF and NDPI brightfield microscopy images, alias whole slide images (WSIs).

From the 1,971 patients we analyzed 10,806 WSIs. We used the SlideToolkit (https://github.com/swvanderlaan/slideToolKit) to quantify seven cellular and extracellular plaque characteristics on culprit lesions from carotid atherosclerotic plaque samples. The number of WSIs is different for every plaque characteristic (Figure 1B). The methodology of the SlideTool kit workflow has been previously published ${ }^{20,21}$. In summary, the SlideToolkit is a collection of open-source scripts that analyzes WSIs according to four steps: acquisition, preparation, tiles and analysis, to obtain quantified results. The main strengths of this method are that it is fully automated, precise and scores excellent regarding reproducibility with intraclass correlation coefficients (ICCS) of $0.92-0.97^{21}$. In the present study, the SlideTookit was used on consecutive sections that were stained following standard procedures with Glycophorin-C (GLYCC) antigens for red blood cells, hematoxylin and eosin (H\&E) for nuclei, elastin Von Giessen (EVG) for elastin fibers, as well as immunohistochemistry (developed with diaminobenzidine (DAB)) for endothelial cells (CD34), neutrophils (CD66b), macrophages (CD68), and smooth muscle cells (SMA). The cellular plaque characteristics (CD34, CD66b, CD68, SMA and HE) were defined as the total number of nucleus containing objects that were positive for their respective stains. The plaque characteristics Glycophorin C (GLYCC) and Elastin (EVG) are defined as the total area in $\mu \mathrm{m}^{2}$ positive for their respective stain. The plaque characteristics are referred to as the name of abbreviation of the staining, e.g., CD34 for endothelial cells.

For the purposes of the current study, in addition to the SlideToolkit measurements, two independent experienced observers manually scored the presence of IPH using previously defined 
medRxiv preprint doi: https://doi.org/10.1101/2021.07.15.21260570; this version posted July 19, 2021. The copyright holder for this preprint (which was not certified by peer review) is the author/funder, who has granted medRxiv a license to display the preprint in perpetuity. It is made available under a CC-BY-NC-ND 4.0 International license .

semi-quantitative methods $s^{4,23,24}$ using H\&E and fibrin stainings. IPH was defined as hemorrhage within the plaque tissue and was rated as being absent or present. The observers were blinded for the results from the Glycophorin C measurements.

\section{Ipsilateral pre-procedural neurological symptoms}

Patients were classified as patients with either an ipsilateral asymptomatic carotid stenosis or ipsilateral symptomatic carotid stenosis prior to surgery, based on their answers to a standardized questionnaire regarding their prior pre-procedural neurological symptoms that were subsequently verified by a detailed review of their medical history. Patients with contralateral symptoms or without any symptoms in the last six months were classified as asymptomatic. Patients were considered symptomatic if they had experienced symptoms due to an acute cerebrovascular event ipsilateral to the carotid stenosis within the last 6 months before surgery. Cerebrovascular events included ischemic stroke, a transient ischemic attack (TIA), amaurosis fugax, ocular ischemic syndrome or a central retinal artery occlusion.

\section{Follow-up analysis for major adverse cardiovascular events (MACE)}

MACE was defined as the three-year postoperative risk of major adverse cardiovascular events including fatal or nonfatal ischemic or hemorrhagic stroke, fatal or nonfatal myocardial infarction (MI) and any cardiovascular death, including sudden cardiac death, fatal rupture of an aortic aneurysm and fatal heart failure or other vascular death. Clinical endpoints were assessed at 1, 2 and 3 years after surgery by means of patient questionnaires and validated by review of medical records; if necessary, general practitioners or other treating physicians were contacted for follow-up data.

\section{Statistical analysis}

Continuous variables were summarized as mean and standard deviation (SD) or as median and interquartile range (IQR). Categorical variables were expressed as frequencies and percentages. Before performing any analyses with the quantified plaque characteristics, technical outliers were identified by calculating the Z-score for the plaque sizes off all samples, samples were excluded if the $Z$-score of the plaque sizes was either $<-3.0$ or $>3.0$. The outliers were largely based on technical artefacts such as low contrast in the WSIs, air bubbles, dust specks or cracks in the glass of the slides that all caused aberrant SlideToolkit measurements.

Subsequently, after the quality control the quantified plaque characteristics and the corresponding plaque sizes of the samples were inverse-rank transformed. Body mass index (BMI), total cholesterol, low density lipids (LDL), high density lipids (HDL), and triglycerides levels were natural log transformed because of skewness. Univariable associations between inverse-rank transformed quantified plaque characteristics measured by the SlideToolkit method and other group variables were explored using Welch Two Sample t-test or One-way ANOVA, as appropriate. The Spearman rank correlation coefficient was used to explore correlation between the quantified plaque characteristics and other continuous variables.

Logistic regression analyses were performed to test the association between Glycophorin C and intraplaque hemorrhage and pre-procedural neurological symptoms. For the association between Glycophorin C and secondary MACE Cox proportional hazard models were performed. We tested the association between the other quantified plaque characteristics with pre-procedural neurological symptoms and secondary MACE as well.

For the logistic regression models and Cox proportional hazard models we made three different models according to a specific structure, model 1 unadjusted, model 2 adjusted for plaque size and model 3 adjusted for plaque size and potential confounders. The confounders were identified by 
medRxiv preprint doi: https://doi.org/10.1101/2021.07.15.21260570; this version posted July 19,2021 . The copyright holder for this preprint (which was not certified by peer review) is the author/funder, who has granted medRxiv a license to display the preprint in perpetuity. It is made available under a CC-BY-NC-ND 4.0 International license.

exploring the association of baseline characteristic, such as risk factor and medication use, with the quantified plaque characteristics and with the different dependent outcome variables (such as preprocedural neurological symptoms and MACE during follow-up). When the baseline characteristic was associated with the quantified plaque characteristic as well as with the outcome variable with a $p$-value of $<0.1$, the baseline characteristic was included as a potential confounder in the final logistic regression or Cox proportional hazard model respectively. Across the selected potential confounders, the proportion of missing values were analyzed (Supplemental Table 1). Missing values of potential confounders were imputed using multivariate imputation by chained equations ${ }^{25}$. When correlated predictors were included in the final model, the best model was selected based on the Akaike Information Criterion (AIC).

Statistical significance threshold was set at a two-sided $p$-value $<0.05$ across all analyses. Analyses were performed using R (v3.6.3 and v4.0.5; The R Foundation for Statistical Computing). 
medRxiv preprint doi: https://doi.org/10.1101/2021.07.15.21260570; this version posted July 19,2021 . The copyright holder for this preprint
(which was not certified by peer review) is the author/funder, who has granted medRxiv a license to display the preprint in perpetuity. It is made available under a CC-BY-NC-ND 4.0 International license.

\section{Results.}

\section{Study population}

A total of 1,971 CEA patients from the Athero-Express Biobank with one or more plaque characteristic(s) measured with the SlideToolkit, were included in the current analysis (mean age $68.8 \pm 9.2$ years, $69.2 \%$ males, $73.6 \%$ symptomatic presentation) (Figure 1 B, Table 1). The majority of patients had one or multiple cardiovascular comorbidities such as hypertension (74.3\%), hypercholesterolemia (69.3\%), diabetes $(23.3 \%)$, or a history of coronary artery disease (CAD) (32.3\%). The median patient in the current study was slightly overweight with a BMI of 26 , and the majority was a current- or ex-smoker (86.1\%). Of the 1,971 patients, 607 patients (30.8\%) were female. Female patients were more often diagnosed with hypertension, had significantly higher levels of total cholesterol, LDL as well as HDL, a significantly worse kidney function, were more often smokers and were more likely to be diagnosed with a critical carotid stenosis (70-99\%), but less likely to use anticoagulants or having a history of CAD, when compared with male patients (Table 1).

\section{Associations of Glycophorin C with sex and other baseline characteristics}

The total area of glycophorin $\mathrm{C}$ was significantly larger in male patients compared to female patients (Figure 2) and remained significantly larger after adjusting for plaque size. Furthermore, we found glycophorin $\mathrm{C}$ to be associated with multiple baseline characteristics such as date of surgery, the use of antihypertensive drugs, history of CAD and ipsilateral carotid stenosis grade (Supplemental 2A). Glycophorin $C$ in male patients was associated with a history of CAD and an ipsilateral degree of carotid stenosis, but not in female patients. Opposed to male patients, hypertension in female patients was associated with glycophorin C (Supplemental 2B-C). The sex-stratified results of the associations of baseline characteristics with other plaque characteristics are listed in Supplemental Figure 1, and Supplemental tables table 2A-C.

\section{Glycophorin and Intraplaque hemorrhage}

Quantified glycophorin C, measured with the SlideToolkit method, was compared to the manual scoring method in which the presence of IPH in atherosclerotic plaques is scored by an experienced pathologist. The total area of glycophorin $\mathrm{C}$ in plaque was larger in plaques with IPH compared to plaques without IPH ( $p<0.001$ ) (Figure 3). Following adjustments for plaque size (Model 2 ), quantified glycophorin $\mathrm{C}$ was associated with plaques with IPH compared to plaque without IPH (OR: 1.47, 95\%Cl:1.20-1.80, $\mathrm{p}<0.001$ ) (Figure 4). Stratified analysis for sex revealed that this was the case for male patients (Model 2: OR 1.61, 95\% Cl 1.25-2.09) but not for female patients (Model 2: OR $1.02,95 \% \mathrm{Cl} 0.71-1.46, \mathrm{p}$-value $=0.92)$ (Figure 4).

\section{Pre-procedural neurological symptoms}

Unadjusted quantified glycophorin was not associated with pre-procedural neurological symptoms when compared with no symptoms prior to surgery. However, after adjustments for plaque size, quantified glycophorin $\mathrm{C}$ was associated with pre-procedural neurological symptoms (Model 2: OR: 1.43, 95\% Cl: 1.15-1.79, $\mathrm{p}=0.002$ ) (Figure 5). After correction for other potential confounders (Supplemental Table 4) in addition to plaque size, the association remained significant (Model 3: OR: 1.27, 95\% Cl: 1.06-1.41, $\mathrm{p}=0.005$ ) (Figure 5). In the subgroup-analysis, a similar association between quantified glycophorin $\mathrm{C}$ and pre-procedural neurological symptoms was found for male patients (Model 3: OR: 1.38, 95\%Cl: 1.10-1.72, $\mathrm{p}=0.005$ ) and for female patients (Model 3: OR:1.32, $95 \% \mathrm{Cl}$ : 1.06-1.65, $p=0.01$ ) (Figure 5). The results of the associations between the other plaque characteristics and pre-procedural neurological symptoms are listed in Supplemental Table $\mathbf{3}$ and Supplemental results. 
medRxiv preprint doi: https://doi.org/10.1101/2021.07.15.21260570; this version posted July 19, 2021. The copyright holder for this preprint

(which was not certified by peer review) is the author/funder, who has granted medRxiv a license to display the preprint in perpetuity.

It is made available under a CC-BY-NC-ND 4.0 International license.

\section{Major adverse cardiovascular events within a 3-year period after surgery}

Univariable as well as multivariable associations of glycophorin C with MACE after CEA were explored, where we defined events occurring up to 3 years after surgery of interest (mean follow-up 2.64 years). Quantified Glycophorin $C$ was associated with a higher risk of MACE within the 3-year period after surgery (HR 1.31,95\% $\mathrm{Cl} 1.01-1.68, p=0.04$, Figure 6 ) independently of plaque size and confounders (Supplemental Table 6). The stratified analysis revealed that this was the case for male patients (HR: $1.50,95 \% \mathrm{Cl} 1.13-1.97, \mathrm{p}=0.004$ ), but not for female patients (HR: $0.70,95 \% \mathrm{Cl} 0.39$ 1.27, $p=0.23$ ) (Figure 6). The results of the associations between the other plaque characteristics and pre-procedural neurological symptoms are listed in Supplemental Table 5 and Supplemental results. 
medRxiv preprint doi: https://doi.org/10.1101/2021.07.15.21260570; this version posted July 19, 2021. The copyright holder for this preprint

(which was not certified by peer review) is the author/funder, who has granted medRxiv a license to display the preprint in perpetuity. It is made available under a CC-BY-NC-ND 4.0 International license

\section{Discussion.}

For the present study of 1,971 patients undergoing CEA, we set up the ExpressScan and investigated the association of quantified plaque glycophorin $\mathrm{C}$ with; (i) the presence of IPH, (ii) ipsilateral preprocedural neurological symptoms, and (iii) risk for MACE following CEA. We showed that quantified glycophorin $C$ independently associates with symptomatic preprocedural symptoms and with an increased three-year postoperative risk of MACE.

We found that plaques in which the presence of IPH had been scored contained a larger area of glycophorin C. However, quantified plaque glycophorin should be seen as a proxy for the degree of $\mathrm{IPH}$, while the manual method scores the presence of IPH merely as present or absent. Thus, due to differences in the scoring method used, quantified glycophorin $\mathrm{C}$ and IPH represent two different aspects of the same underlying process. Although the presence of intraplaque hemorrhages in CEA specimens is extensively studied in relation to neurological symptoms before CEA $^{22}$ or as a predictor for general cardiovascular morbidity and mortality ${ }^{4,12}$, the degree of IPH has not been considered before. The current study identifies quantified plaque glycophorin $\mathrm{C}$ as a novel marker of ipsilateral pre-procedural symptoms and MACE following CEA.

We can only speculate about the ways the accumulation of erythrocytes, as measured by quantified plaque glycophorin C, may play a role in vulnerable plaque pathophysiology. Erythrocytes in the plaque are believed to originate from leaky microvessels in the intima, that arise from the adventitia, as a result from angiogenesis that is induced in the early stages of atherosclerosis as a by-product of plaque inflammation ${ }^{26}$. These neo-capillaries are considered leaky and immature because the newly formed thin-walled microvessels are lined with discontinuous abnormal endothelial cells that allow the extravasation of leukocytes and erythrocytes ${ }^{27}$. Several studies have suggested that intraplaque hemorrhages are associated with an increased density of microvessels ${ }^{4}$, as intraplaque hemorrhages have been identified in the near proximity of these immature microvessels ${ }^{28}$. Moreover, the extravasation of erythrocyte from these microvessels is commonly observed in atherosclerotic plaque with intraplaque hemorrhages ${ }^{29}$. In addition to the close relation with neo-capillaries there is another mechanism whereby the extravasation of erythrocyte contributes to the vulnerability and the eventual destabilization of plaque. Erythrocyte membranes have been demonstrated within the necrotic core of human atherosclerotic plaque ${ }^{17}$. Due the high cholesterol content of erythrocyte membranes that exceeds that of all other cells in the body, with lipids constituting $40 \%$ of their weight ${ }^{30}$, erythrocyte membranes are capable of providing a substantial amount of lipid to the necrotic core. Parallel to the rapid increase in lipids, there is an increase in the density of macrophages, raising the possibility that hemorrhage itself serves as an inflammatory stimulus ${ }^{17}$. Furthermore, macrophages were frequently found to contain hemoglobin and iron, suggesting that phagocytosis of erythrocytes may contribute to the formation of foam cells ${ }^{31}$. To conclude, by contributing to the deposition of free cholesterol, macrophage infiltration, and enlargement of the necrotic core, the accumulation of erythrocyte membranes within an atherosclerotic plaque may represent a potent atherogenic stimulus. As such, quantified glycophorin C, i.e., the degree of IPH, may represent a marker of atherosclerotic evolution towards a plaque at-risk.

The accumulation of erythrocyte and erythrocyte membranes within a plaque can be visualized by staining against glycophorins. This method has been used in a small number of studies with a limited sample size as a strategy to quantify IPH, in these studies a glycophorin score that consisted of four categories was used, higher scores indicated a greater total surface area that was positively stained for glycophorin ${ }^{17-19}$. The associations of the glycophorin score with either symptomatic plaque, or cardiovascular outcome following surgery were not studied. However, higher glycophorin scores have been associated with more advanced atherosclerotic plaque, a larger lipid core, higher microvessel density and higher macrophage density ${ }^{17,18}$. Our study is the first study to report that the total area of glycophorin is greater in plaque from symptomatic patients than asymptomatic 
medRxiv preprint doi: https://doi.org/10.1101/2021.07.15.21260570; this version posted July 19, 2021. The copyright holder for this preprint

(which was not certified by peer review) is the author/funder, who has granted medRxiv a license to display the preprint in perpetuity. It is made available under a CC-BY-NC-ND 4.0 International license.

patients. Moreover, our finding of an association between quantified plaque glycophorin $\mathrm{C}$ and future MACE after CEA shows that quantified plaque glycophorin, has prognostic value. Quantified plaque glycophorin $\mathrm{C}$ might thus be able to serve as a marker for plaque instability and progression in other vascular territories after surgery, and it might be able to identify those patients that have a high residual risk for secondary events following CEA.

Using the slideToolkit method we have quantified the usual suspects of plaque composition that have been examined using the semi-quantitative method such as IPH, macrophages and SMC content ${ }^{4}$. In addition, measurements like CD66b for neutrophils, HE for cell nuclei and EVG for elastin fibers were included. We found that neutrophils stained with the CD66b marker were independently associated with pre-procedural symptomatic plaque, which is in accordance with previous findings that neutrophils in carotid plaque are associated with characteristics of rupture prone lesions ${ }^{32,33}$. In an earlier study by our group, the plaque of female patients contained significantly fewer neutrophils compared to plaque of male patients ${ }^{32}$. This may explain why we found that quantified CD66b adjusted for confounders was associated with pre-procedural neurological symptoms in male patients but not in female patients. Furthermore, we found that quantified EVG was independently associated with a higher risk for MACE following CEA. During the progression of atherosclerotic plaque, elastolysis and ineffective elastogenesis favor the accumulation of tropo-elastin, rather than cross-linked elastin, in atherosclerotic plaque ${ }^{34}$. In contrast with cross-linked elastin, tropo-elastin has been associated with plaque progression and instability in atherosclerotic models ${ }^{34}$. This might be a possible explanation for our finding in the current study that quantified EVG was associated with an increased risk for MACE following CEA.

The results regarding differences in plaque composition between males and females is consistent with previous studies ${ }^{35}$. We found that plaque from male patients not only contained more glycophorin C, but also more neutrophils (CD66b staining) and were associated with more cellularity (HE staining). This is somewhat equivalent to our previous findings that carotid plaque from male patients showed a higher prevalence of $\mathrm{IPH}^{36}$. In addition, the presence of IPH in a previous study was independently associated with an increased risk for MACE following CEA in male patient but not in female patients ${ }^{36}$, this is identical to our findings in the sex-stratified analyses regarding quantified glycophorin C, and its association with an increased postoperative risk for MACE.

There are a few limitations to our approach. First as the Athero-Express Biobank represents a retrospective study design, we can only speculate about the causality of our findings. Second, in our study we were not able to reproduce certain histological associations, such as the association of macrophage-rich plaques with severe pre-procedural neurological symptoms or that of SMC-rich plaque with absent or mild pre-procedural neurological symptoms. The semi-quantitative method does take location into account and is limited to areas, where the new method scores every cell or plaque area regardless of location. Although, both methods rely on the quantity, a one-to-one comparison is therefore not correct. With the quantification of plaque characteristics using WSIs we are exploring new territory, including the location of cell types within the WSI analysis or immunostaining for subtypes might be beneficial and this needs more research. Future studies will look at cell ratios and location in relation to each other. Next, the quantitative assessment of the plaque characteristics is based on the analysis of a single WSI, rather than a serial assessment of various WSIs throughout the plaque. We deem it unlikely that this strongly influences the results found, since in histological assessment studies using the semi-quantitative classification method there was good overall agreement between three to five millimeter sections ${ }^{14,24}$. However, this may vary depending on the method used and the specific plaque feature being scored. Furthermore, although we describe one of the largest groups of women operated by CEA, addressing confounding in the multivariable longitudinal analysis for each plaque characteristics could not be done convincingly without violating power calculations for some of the plaque characteristics. These sex- 
medRxiv preprint doi: https://doi.org/10.1101/2021.07.15.21260570; this version posted July 19, 2021. The copyright holder for this preprint (which was not certified by peer review) is the author/funder, who has granted medRxiv a license to display the preprint in perpetuity. It is made available under a CC-BY-NC-ND 4.0 International license

stratified results need to be interpreted in the light of the confidence intervals, to avoid misleading conclusions ${ }^{37}$. In addition, for the longitudinal analyses we have used MACE as a composite outcome and we were not able to perform analyses on separate outcomes such as (non)fatal stroke or non(fatal) myocardial infarction due to a limited number of events.

This is the first study in a large prospective biobank that used the reproducible, precise and fully automated slideToolkit method on a larger scale to quantify multiple plaque characteristics. Our results support the application of this method in large scale '-omics' studies and for the validation of non-invasive imaging techniques that heavily rely on reliable histological scoring methods as the gold standard comparison. The current study underscores that the slideToolkit can be used to quantify multiple plaque characteristics. We affirm that the slideToolkit enables further and broader characterization of plaque composition in a reliable manner, that enables the exploration of new biomarkers. Using the slide Tool kit method we may be able to identify more histological markers, besides quantified glycophorin $C$ that can be used to identify male patients with a high residual cardiovascular risk for developing MACE following CEA.

To conclude, our study shows that quantified glycophorin C, as a proxy for the degree of IPH, is independently associated with symptomatic preprocedural symptoms and with an increased threeyear postoperative risk of MACE following carotid endarterectomy. Our findings emphasize that quantifying the degree of IPH with glycophorin $\mathrm{C}$ identifies and measures a potent atherogenic stimulus which may serve as a biomarker for the identification of male patients with a higher residual risk for secondary MACE following CEA. 
medRxiv preprint doi: https://doi.org/10.1101/2021.07.15.21260570; this version posted July 19,2021 . The copyright holder for this preprint (which was not certified by peer review) is the author/funder, who has granted medRxiv a license to display the preprint in perpetuity. It is made available under a CC-BY-NC-ND 4.0 International license .

Table 1. Baseline characteristics

\begin{tabular}{|c|c|c|c|c|c|}
\hline & & Full cohort & Male & Female & p-value \\
\hline & & $N=1971$ & $N=1364$ & $N=607$ & \\
\hline Age (mean (SD)) & & $68.8(9.2)$ & $68.7(8.9)$ & $69.0(9.9)$ & 0.52 \\
\hline \multirow[t]{2}{*}{ Gender - n (\%) } & Male & $1364(69.2)$ & & & \\
\hline & Female & $607(30.8)$ & & & \\
\hline Systolic BP (mean (SD)) - mmHg & & $154(26)$ & $153(26)$ & $155(27)$ & 0.41 \\
\hline Diastolic BP (mean (SD)) - mmHg & & $82(14)$ & $82(14)$ & $81(13)$ & 0.20 \\
\hline Hypertension - n (\%) & & $1432(74.3)$ & $960(72.1)$ & $472(79.2)$ & 0.001 \\
\hline Diabetes mellitus - $\mathrm{n}(\%)$ & & $460(23.3)$ & $332(24.3)$ & $128(21.1)$ & 0.13 \\
\hline Hypercholesterolemia - n (\%) & & $1265(69.3)$ & $877(69.1)$ & $388(69.7)$ & 0.86 \\
\hline Total cholesterol (median [IQR]) - mmol/L & & $4.64[3.90,5.50]$ & $4.52[3.80,5.31]$ & $5.00[4.01,5.83]$ & $<0.001$ \\
\hline $\mathrm{HDL}$ (median [IQR]) - mmol/L & & $2.70[2.08,3.40]$ & $2.62[2.02,3.30]$ & $2.79[2.19,3.69]$ & 0.004 \\
\hline LDL (median [IQR]) - mmol/L & & $1.10[0.90,1.38]$ & $1.06[0.87,1.29]$ & $1.24[1.03,1.53]$ & $<0.001$ \\
\hline Triglycerides (median [IQR]) - mmol/L & & $1.41[1.04,2.05]$ & $1.45[1.05,2.07]$ & $1.40[1.00,1.95]$ & 0.14 \\
\hline BMI (median [IQR]) - kg/m2 & & $26.0[24.1,28.5]$ & $26.11[24.2,28.4]$ & $25.86[23.4,28.7]$ & 0.12 \\
\hline eGFR, (mean (SD)) - ml/min/1.73m2 & & $72.40(20.52)$ & $73.60(20.56)$ & $69.70(20.17)$ & $<0.001$ \\
\hline \multirow[t]{3}{*}{ Smoking Status - n (\%) } & Current smoker & $672(35.8)$ & $441(33.7)$ & $231(40.7)$ & $<0.001$ \\
\hline & Ex-smoker & $944(50.3)$ & $729(55.6)$ & $215(37.9)$ & \\
\hline & Never smoked & $262(14.0)$ & $140(10.7)$ & $122(21.5)$ & \\
\hline History of coronary artery disease - $\mathrm{n}(\%)$ & & $634(32.2)$ & $491(36.0)$ & $143(23.6)$ & $<0.001$ \\
\hline History of peripheral artery disease - $\mathrm{n}(\%)$ & & $422(21.4)$ & $302(22.1)$ & $120(19.8)$ & 0.27 \\
\hline History of peripheral intervention(s) - $n$ (\%) & & $397(20.2)$ & $264(19.4)$ & $133(22.0)$ & 0.21 \\
\hline History of stroke or TIA - $\mathrm{n}(\%)$ & & $1580(80.2)$ & $1089(79.8)$ & $491(80.9)$ & 0.63 \\
\hline Use of antihypertensive drugs - $\mathrm{n}(\%)$ & & $1511(76.8)$ & $1052(77.2)$ & $459(75.9)$ & 0.54 \\
\hline Use of statins - $n(\%)$ & & $1550(78.8)$ & $1070(78.6)$ & $480(79.3)$ & 0.74 \\
\hline Use of antiplatelet drugs - $\mathrm{n}(\%)$ & & $1746(88.9)$ & $1196(88.0)$ & $550(90.9)$ & 0.07 \\
\hline Use of oral anticoagulant drugs - $n$ (\%) & & $239(12.2)$ & $182(13.4)$ & $57(9.4)$ & 0.02 \\
\hline \multirow[t]{3}{*}{ Ipsilateral pre-operative stenosis - $\mathrm{n}(\%)$} & $0-50 \%$ & $10(0.5)$ & $8(0.6)$ & $2(0.3)$ & 0.04 \\
\hline & $50-70 \%$ & $157(8.2)$ & $122(9.2)$ & $35(5.9)$ & \\
\hline & $70-99 \%$ & $1757(91.3)$ & $1198(90.2)$ & $559(93.8)$ & \\
\hline \multirow[t]{2}{*}{ Contralateral stenosis - $\mathrm{n}(\%)$} & $0-50 \%$ & $975(55.3)$ & $663(54.2)$ & $312(57.8)$ & 0.18 \\
\hline & $50-100 \%$ & $788(44.7)$ & $560(45.8)$ & $228(42.2)$ & \\
\hline \multirow{4}{*}{$\begin{array}{l}\text { Pre-procedural neurological symptoms - } n \\
\text { (\%) }\end{array}$} & Asymptomatic & $502(26.4)$ & $371(28.3)$ & $131(22.3)$ & 0.06 \\
\hline & Ocular & $330(17.4)$ & $219(16.7)$ & $111(18.9)$ & \\
\hline & TIA & $651(34.3)$ & $282(21.5)$ & $134(22.8)$ & \\
\hline & Stroke & $416(21.9)$ & $440(33.5)$ & $211(35.9)$ & \\
\hline
\end{tabular}

Data are given as a proportion of the group (\%), as mean with standard deviation (SD) in case of normally distributed data, or as median with interquartile range (IQR) in case of not normally distributed data. BP= blood pressure; $\mathrm{HDL}=$ high density lipoprotein; $L D L=$ low density lipoprotein; $B M I=$ body mass index; eGFR = estimated Glomerular filtration rate; TIA = transient ischemic attack. 
medRxiv preprint doi: https://doi.org/10.1101/2021.07.15.21260570; this version posted July 19, 2021. The copyright holder for this preprint (which was not certified by peer review) is the author/funder, who has granted medRxiv a license to display the preprint in perpetuity. It is made available under a CC-BY-NC-ND 4.0 International license.

Figure 1 A. Study design and flowchart of study participants. (A) Graphical illustration of the study design. Created with BioRender.com.

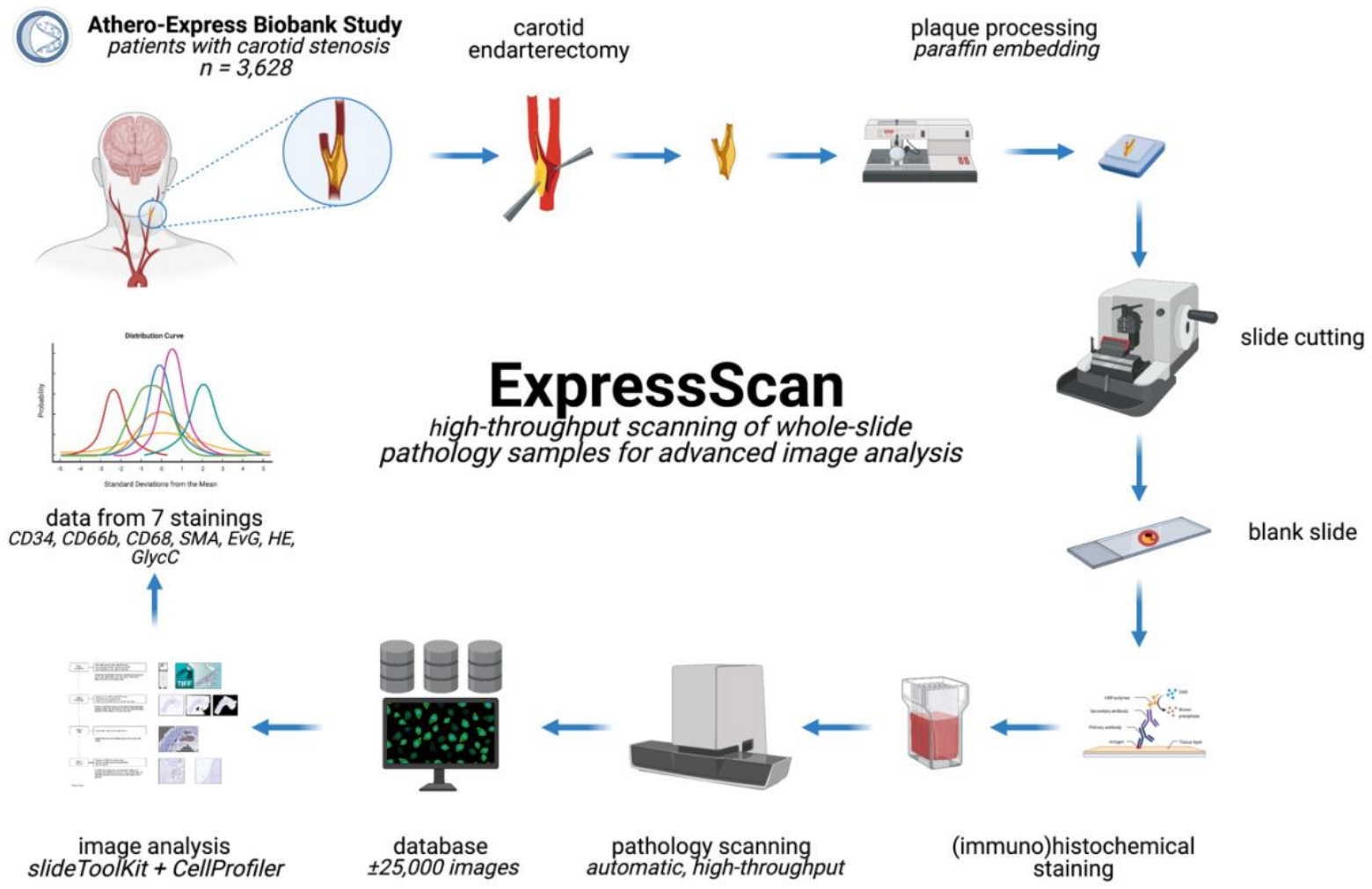

Figure 1 B. Study design and flowchart of study participants. (B) Number of individuals included in the current study and sample size across different plaque characteristics.

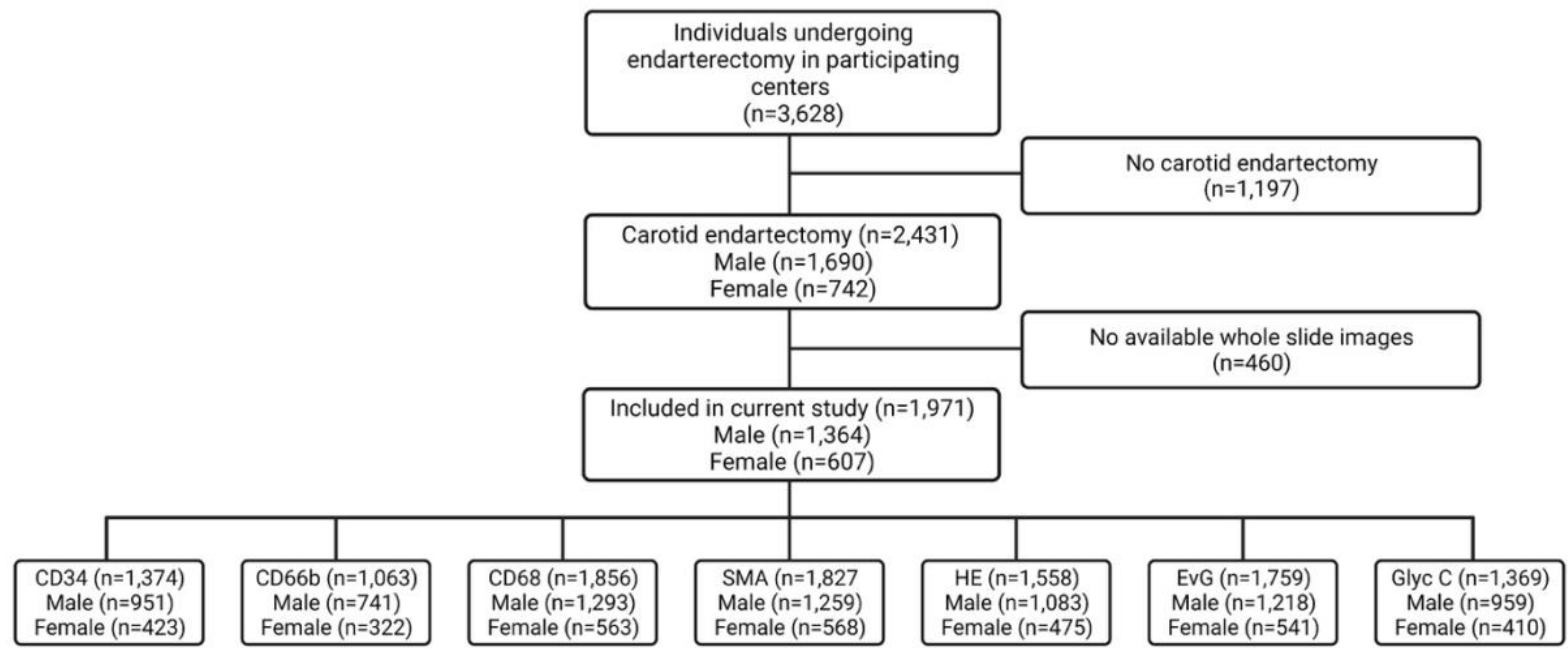


medRxiv preprint doi: https://doi.org/10.1101/2021.07.15.21260570; this version posted July 19, 2021. The copyright holder for this preprint (which was not certified by peer review) is the author/funder, who has granted medRxiv a license to display the preprint in perpetuity. It is made available under a CC-BY-NC-ND 4.0 International license.

Figure 2. Univariable association between glycophorin $C$ and gender. The total area of glycophorin $C$ (inverse rank transformed) was significantly larger in male patients in comparison with female patients $(p<0.001)$.

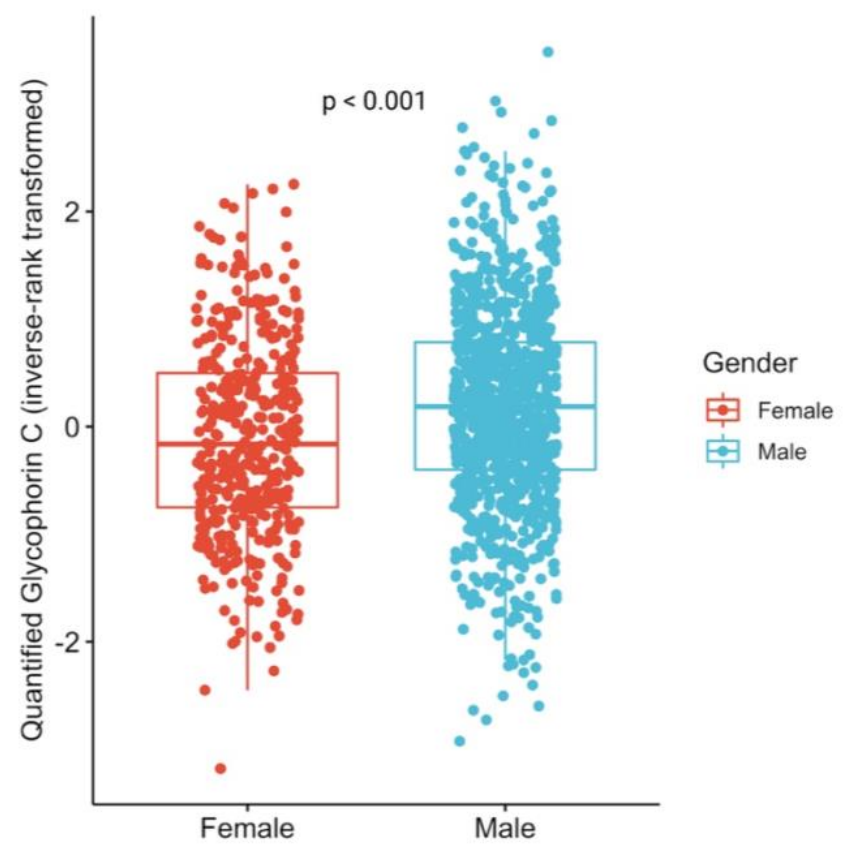


medRxiv preprint doi: https://doi.org/10.1101/2021.07.15.21260570; this version posted July 19, 2021. The copyright holder for this preprint (which was not certified by peer review) is the author/funder, who has granted medRxiv a license to display the preprint in perpetuity. It is made available under a CC-BY-NC-ND 4.0 International license.

Figure 3. Univariable association between glycophorin $\mathrm{C}$ and the presence of IPH. The total area of glycophorin $\mathrm{C}$ (inverse rank transformed) was significantly larger in plaque with IPH when compared to plaque without IPH.

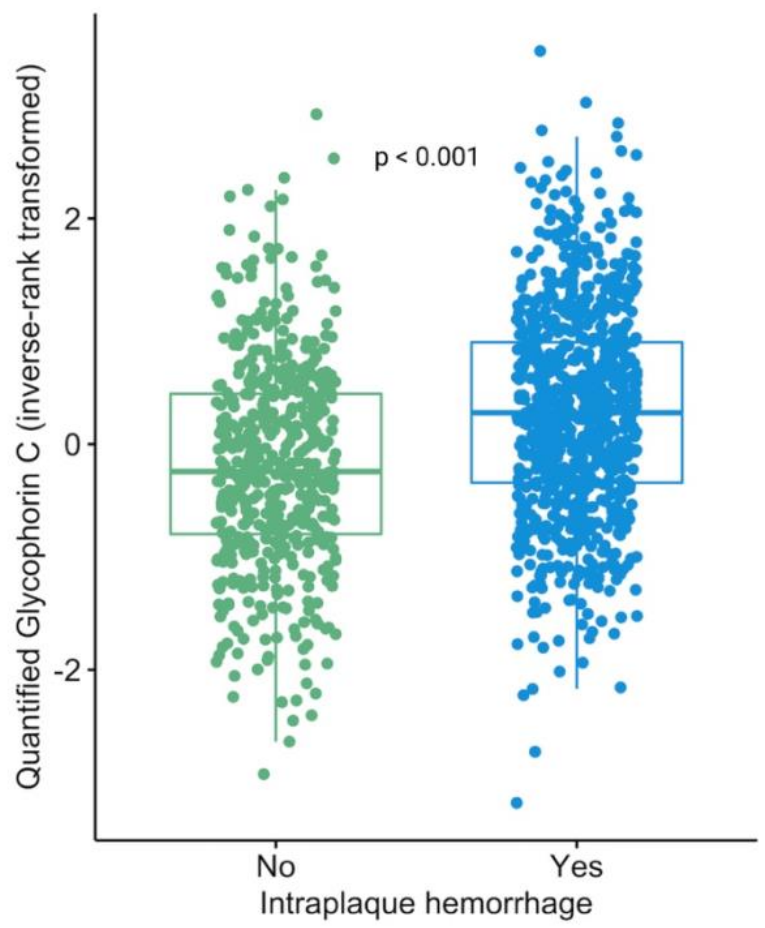

Figure 4. Quantified plaque glycophorin C is associated with Intraplaque hemorrhage. Univariable and multivariable associations of glycophorin $\mathrm{C}$ with intraplaque hemorrhage, as derived from logistic regression analyses (Model 1: unadjusted absolute values, Model 2: adjusted for plaque size). Glycophorin $C$ plaque areas are inverse-rank transformed in the analyses.

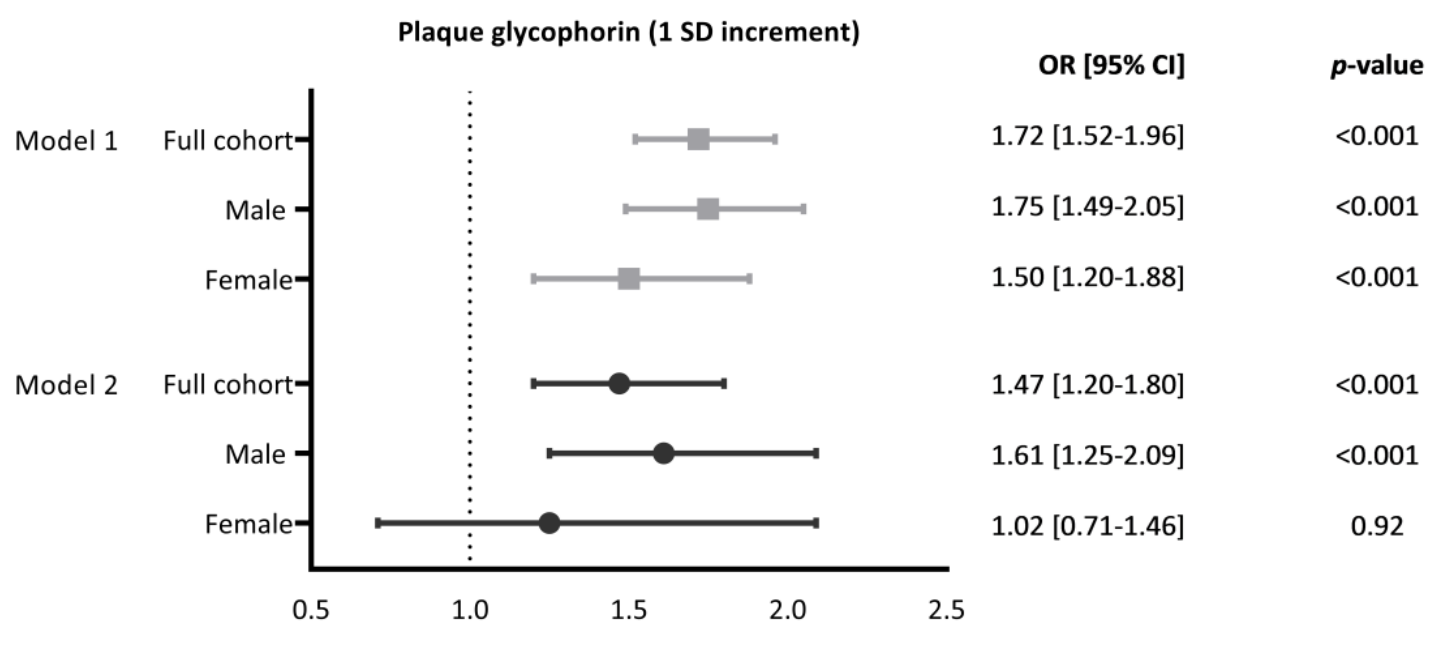

OR $(95 \% \mathrm{Cl})$ for presence of intraplaque hemorrhage 
medRxiv preprint doi: https://doi.org/10.1101/2021.07.15.21260570; this version posted July 19, 2021. The copyright holder for this preprint (which was not certified by peer review) is the author/funder, who has granted medRxiv a license to display the preprint in perpetuity. It is made available under a CC-BY-NC-ND 4.0 International license.

Figure 5. Quantified glycophorin C is associated with pre-procedural symptoms. Univariable and multivariable associations of glycophorin $\mathrm{C}$ with pre-procedural symptoms (Asymptomatic versus asymptomatic), as derived from logistic regression analyses. Model 1: unadjusted, Model 2 adjusted for plaque size and Model 3 adjusted for plaque size and additional confounders (Supplemental Table 3). Glycophorin C is inverse rank transformed in all analyses.

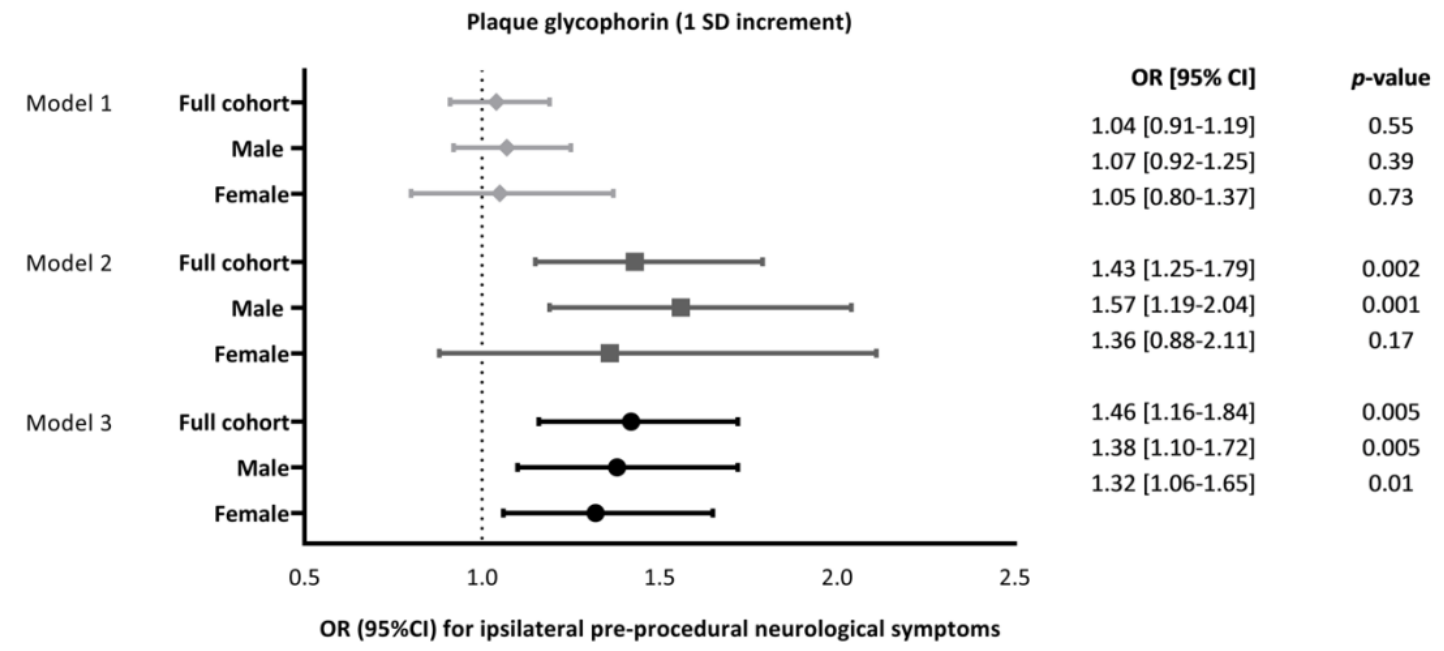


medRxiv preprint doi: https://doi.org/10.1101/2021.07.15.21260570; this version posted July 19, 2021. The copyright holder for this preprint (which was not certified by peer review) is the author/funder, who has granted medRxiv a license to display the preprint in perpetuity. It is made available under a CC-BY-NC-ND 4.0 International license.

Figure 6. Quantified plaque glycophorin $\mathrm{C}$ is associated with new major cardiovascular adverse events within 3-years after surgery. Univariable and multivariable associations of glycophorin C with MACE within 3-years after surgery, as derived from Cox regression analyses (Model 1: unadjusted absolute values, Model 2: adjusted for plaque size and Model 3: adjusted for plaque size and confounders (Supplemental Table 6)).

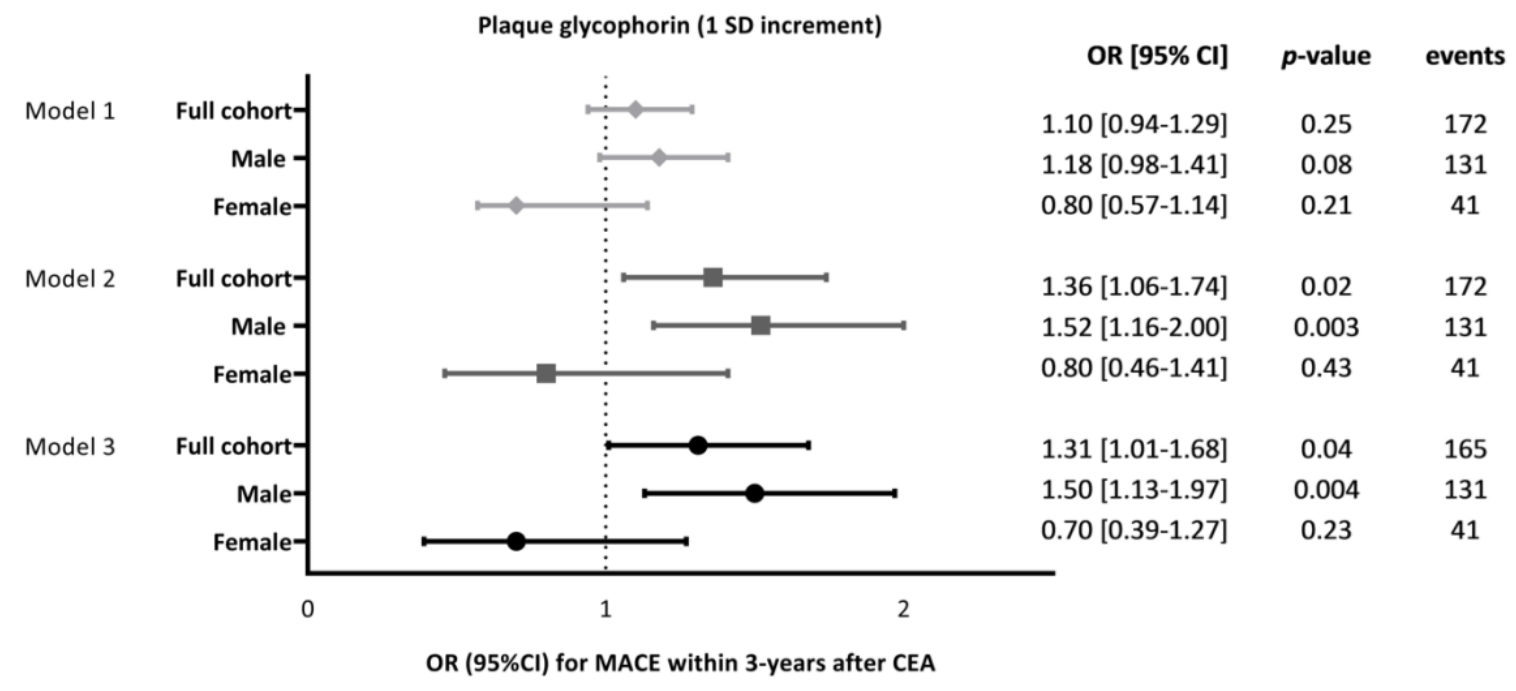


medRxiv preprint doi: https://doi.org/10.1101/2021.07.15.21260570; this version posted July 19, 2021. The copyright holder for this preprint (which was not certified by peer review) is the author/funder, who has granted medRxiv a license to display the preprint in perpetuity. It is made available under a CC-BY-NC-ND 4.0 International license

\section{References.}

1 Naylor AR, Ricco JB, de Borst GJ, Debus S, de Haro J, Halliday A, et al. Editor's Choice - Management of Atherosclerotic Carotid and Vertebral Artery Disease: 2017 Clinical Practice Guidelines of the European Society for Vascular Surgery (ESVS). Eur J Vasc Endovasc Surg 2018;55(1):3-81. Doi: 10.1016/j.ejvs.2017.06.021. Van Lammeren GW, Catanzariti LM, Peelen LM, De Vries JPPM, De Kleijn DPV, Moll FL, et al. Clinical prediction rule to estimate the absolute 3-year risk of major cardiovascular events after carotid endarterectomy. Stroke 2012;43(5):1273-8. Doi: 10.1161/STROKEAHA.111.647958. Van Koeverden ID, Van Haelst STW, Haitjema S, De Vries J-PPM, Moll FL, Den Ruijter HM, et al. Timedependent trends in cardiovascular adverse events during follow-up after carotid or iliofemoral endarterectomy 2017. Doi: 10.1002/bjs.10576. Hellings WE, Peeters W, Moll FL, Piers S, Van Setten J, Van Der Spek PJ, et al. Composition of carotid atherosclerotic plaque is associated with cardiovascular outcome: A prognostic study. Circulation 2010;121(17):1941-50. Doi: 10.1161/CIRCULATIONAHA.109.887497. Hansson GK. Inflammation, Atherosclerosis, and Coronary Artery Disease. N Engl J Med 2005;352(16):1685-95. Doi: 10.1056/nejmra043430.

6 Vink A, Schoneveld AH, Richard W, De Kleijn DPV, Falk E, Borst C, et al. Plaque burden, arterial remodeling and plaque vulnerability: Determined by systemic factors? J Am Coll Cardiol 2001;38(3):718-23. Doi: 10.1016/S0735-1097(01)01444-9. Plaques of Lower Peripheral Arteries and Their Association with Cardiovascular Disease: An Autopsy Study. J Atheroscler Thromb 2017;24:921-7. Doi: 10.5551/jat.39669.

8 Bentzon JF, Otsuka F, Virmani R, Falk E. Mechanisms of plaque formation and rupture. Circ Res 2014;114(12):1852-66. Doi: 10.1161/CIRCRESAHA.114.302721.

9 Libby P, Pasterkamp G. Requiem for the 'vulnerable plaque.' Eur Heart J 2015;36(43):ehv349. Doi: 10.1093/eurheartj/ehv349.

10 Michel JB, Virmani R, Arbustini E, Pasterkamp G. Intraplaque haemorrhages as the trigger of plaque vulnerability. Eur Heart J 2011;32(16):1977-85. Doi: 10.1093/eurheartj/ehr054.

Derksen WJM, Peeters W, van Lammeren GW, Tersteeg C, de Vries JPPM, de Kleijn DPV, et al. Different stages of intraplaque hemorrhage are associated with different plaque phenotypes: A large histopathological study in 794 carotid and 276 femoral endarterectomy specimens. Atherosclerosis 2011;218(2):369-77. Doi: 10.1016/j.atherosclerosis.2011.07.104.

12 Vrijenhoek JEP, Den Ruijter HM, De Borst GJ, de Kleijn DPV, De Vries J-PPM, Bots ML, et al. Sex Is Associated With the Presence of Atherosclerotic Plaque Hemorrhage and Modifies the Relation Between Plaque Hemorrhage and Cardiovascular Outcome. Stroke 2013;44(12):3318-23. Doi: 10.1161/STROKEAHA.113.002633.

13 Redgrave JNE, Lovett JK, Gallagher PJ, Rothwell PM. Histological assessment of 526 symptomatic carotid plaques in relation to the nature and timing of ischemic symptoms: The Oxford plaque study. Circulation 2006;113(19):2320-8. Doi: 10.1161/CIRCULATIONAHA.105.589044.

14 Lovett JK, Gallagher PJ, Rothwell PM. Reproducibility of histological assessment of carotid plaque: Implications for studies of carotid imaging. Cerebrovasc Dis 2004;18(2):117-23. Doi: 10.1159/000079259. de Oliveira S, Saldanha C. An overview about erythrocyte membrane. Clin Hemorheol Microcirc 2010;44(1):63-74. Doi: 10.3233/CH-2010-1253.

16 Yawata Y. Cell Membrane: The Red Blood Cell as a Model. Wiley; 2003.

17 Kolodgie FD, Gold HK, Burke AP, Fowler DR, Kruth HS, Weber DK, et al. Intraplaque Hemorrhage and Progression of Coronary Atheroma. N Engl J Med 2003;349(24):2316-25. Doi: 10.1056/NEJMoa035655. Gössl M, Versari D, Hildebrandt HA, Bajanowski T, Sangiorgi G, Erbel R, et al. Segmental Heterogeneity of Vasa Vasorum Neovascularization in Human Coronary Atherosclerosis. JACC Cardiovasc Imaging 2010;3(1):32-40. Doi: 10.1016/j.jcmg.2009.10.009.

19 Hao H, lihara K, Ishibashi-Ueda H, Saito F, Hirota S. Correlation of thin fibrous cap possessing adipophilin-positive macrophages and intraplaque hemorrhage with high clinical risk for carotid endarterectomy: Clinical article. J Neurosurg 2011;114(4):1080-7. Doi: 10.3171/2010.8.JNS10423. Nelissen BGL, van Herwaarden JA, Moll FL, van Diest PJ, Pasterkamp G. SlideToolkit: An Assistive Toolset for the Histological Quantification of Whole Slide Images. PLoS One 2014;9(11):e110289. Doi: 10.1371/journal.pone.0110289.

21 Vrijenhoek JEP, Nelissen BGL, Velema E, Vons K, de Vries J-PPM, Eijkemans MJC, et al. High 
medRxiv preprint doi: https://doi.org/10.1101/2021.07.15.21260570; this version posted July 19, 2021. The copyright holder for this preprint

(which was not certified by peer review) is the author/funder, who has granted medRxiv a license to display the preprint in perpetuity. It is made available under a CC-BY-NC-ND 4.0 International license .

Reproducibility of Histological Characterization by Whole Virtual Slide Quantification; An Example Using Carotid Plaque Specimens. PLoS One 2014;9(12):e115907. Doi: 10.1371/journal.pone.0115907. Gao P, Chen ZQ, Bao YH, Jiao LQ, Ling F. Correlation between carotid intraplaque hemorrhage and clinical symptoms: Systematic review of observational studies. Stroke 2007:2382-90. Doi: 10.1161/STROKEAHA.107.482760. Verhoeven BAN, Velema E, Schoneveld AH, Vries JPPM de., de Bruin P, Seldenrijk CA, et al. Atheroexpress: Differential atherosclerotic plaque expression of mRNA and protein in relation to cardiovascular events and patient characteristics. Rationale and design. Eur J Epidemiol 2004;19(12):1127-33. Doi: 10.1007/s10564-004-2304-6. Hellings WE, Pasterkamp G, Vollebregt A, Seldenrijk CA, De Vries J-PPM, Velema E, et al. Intraobserver and interobserver variability and spatial differences in histologic examination of carotid endarterectomy specimens. J Vasc Surg 2007;46(6):1147-54. Doi: 10.1016/j.jvs.2007.08.018. van Buuren S, Groothuis-Oudshoorn K. mice: Multivariate imputation by chained equations in R. J Stat Softw 2011;45(3):1-67. Doi: 10.18637/jss.v045.i03. Ribatti D, Levi-Schaffer F, Kovanen PT. Inflammatory angiogenesis in atherogenesis - A double-edged sword. Ann Med 2008;40(8):606-21. Doi: 10.1080/07853890802186913.

Sluimer JC, Kolodgie FD, Bijnens APJJ, Maxfield K, Pacheco E, Kutys B, et al. Thin-Walled Microvessels in Human Coronary Atherosclerotic Plaques Show Incomplete Endothelial Junctions. Relevance of Compromised Structural Integrity for Intraplaque Microvascular Leakage. J Am Coll Cardiol 2009;53(17):1517-27. Doi: 10.1016/j.jacc.2008.12.056.

28 Virmani R, Kolodgie FD, Burke AP, Finn A V., Gold HK, Tulenko TN, et al. Atherosclerotic plaque progression and vulnerability to rupture: Angiogenesis as a source of intraplaque hemorrhage. Arterioscler Thromb Vasc Biol 2005;25(10):2054-61. Doi: 10.1161/01.ATV.0000178991.71605.18. Virmani R, Roberts WC. Extravasated erythrocytes, iron, and fibrin in atherosclerotic plaques of coronary arteries in fatal coronary heart disease and their relation to luminal thrombus: Frequency and significance in 57 necropsy patients and in 2958 five $\mathrm{mm}$ segments of 224 majo. Am Heart J 1983;105(5):788-97. Doi: 10.1016/0002-8703(83)90242-9. plaques: Where does it come from? Curr Opin Lipidol 2007:500-7. Doi:

10.1097/MOL.0b013e3282efa35b.

Kockx MM, Cromheeke KM, Knaapen MWM, Bosmans JM, De Meyer GRY, Herman AG, et al. Phagocytosis and macrophage activation associated with hemorrhagic microvessels in human atherosclerosis. Arterioscler Thromb Vasc Biol 2003;23(3):440-6. Doi: 10.1161/01.ATV.0000057807.28754.7F. Ionita MG, Van Den Borne P, Catanzariti LM, Moll FL, De Vries JPPM, Pasterkamp G, et al. High neutrophil numbers in human carotid atherosclerotic plaques are associated with characteristics of rupture-prone lesions. Arterioscler Thromb Vasc Biol 2010;30(9):1842-8. Doi: 10.1161/ATVBAHA.110.209296.

33 Naruko T, Ueda M, Haze K, Van der Wal AC, Van der Loos CM, Itoh A, et al. Neutrophil infiltration of culprit lesions in acute coronary syndromes. Circulation 2002;106(23):2894-900. Doi: 10.1161/01.CIR.0000042674.89762.20. Phinikaridou A, Lacerda S, Lavin B, Andia ME, Smith A, Saha P, et al. Tropoelastin: A novel marker for plaque progression and instability. Circ Cardiovasc Imaging 2018;11(8). Doi: 10.1161/CIRCIMAGING.117.007303. Wendorff C, Wendorff H, Pelisek J, Tsantilas P, Zimmermann A, Zernecke A, et al. Carotid Plaque Morphology Is Significantly Associated with Sex, Age, and History of Neurological Symptoms. Stroke 2015;46(11):3213-9. Doi: 10.1161/STROKEAHA.115.010558. Vrijenhoek JEP, Den Ruijter HM, De Borst GJ, De Kleijn DPV, De Vries JPPM, Bots ML, et al. Sex is associated with the presence of atherosclerotic plaque hemorrhage and modifies the relation between plaque hemorrhage and cardiovascular outcome. Stroke 2013;44(12):3318-23. Doi: 10.1161/STROKEAHA.113.002633. 
medRxiv preprint doi: https://doi.org/10.1101/2021.07.15.21260570; this version posted July 19, 2021. The copyright holder for this preprint

(which was not certified by peer review) is the author/funder, who has granted medRxiv a license to display the preprint in perpetuity.

It is made available under a CC-BY-NC-ND 4.0 International license .

\section{Funding.}

This work was supported by the Netherlands Cardiovascular Research Initiative: an initiative with support of the Dutch Heart Foundation (CVON-GENIUS-2 to GP and SWvdL). We are thankful for the support of the ERACVD program 'druggable-MI-targets' (grant number: 01KL1802), the EU H2020 TO_AITION (grant number: 848146), EU H2020 Taxinomisis (grant number 755320 JM, GP, GJB DdK), and the Leducq Fondation 'PlaqOmics'.

\section{Author contributions}

Study design: JM, DK, GB, SH, SWvdL

Data collection: JM, ND, MV, SWvdL, GP

Sample measurements: ND, YS, CM, SWvdL

Data analysis and interpretation: JM, TS, MV, DK, MM, HR, GP, YS, CM, SH, SWvdL

Drafting the article and figures: JM, MV, DK, GB, SH, SWvdL

Critical revisions and final approval: JM, TS, MV, ND, YS, CM, GP, MM, HR, DK, GB, SH, SWvdL

\section{Acknowledgements.}

We would also like to thank all the (former) employees involved in the Athero-Express Biobank Study of the Departments of Surgery of the St. Antonius Hospital Nieuwegein and University Medical Center Utrecht for their continuing work. Lastly, we would like to thank all participants of the Athero-Express Biobank Study; without you these kinds of studies would not be possible. 